\title{
BTK blocks the inhibitory effects of MDM2 on p53 activity
}

\author{
Miran Rada ${ }^{1}$, Mohammad Althubiti ${ }^{1,2}$, Akang E. Ekpenyong-Akiba ${ }^{1}$, Koon-Guan \\ Lee $^{3}$, Kong Peng Lam ${ }^{3}$, Olga Fedorova ${ }^{4}$, Nickolai A. Barlev ${ }^{4}$ and Salvador Macip ${ }^{1}$ \\ ${ }^{1}$ Department of Molecular and Cell Biology, Mechanisms of Cancer and Aging Laboratory, University of Leicester, Leicester, UK \\ ${ }^{2}$ Department of Biochemistry, Faculty of Medicine, Umm Al-Qura University, Mecca, Saudi Arabia \\ ${ }^{3}$ Bioprocessing Technology Institute, A*STAR, Singapore \\ ${ }^{4}$ Institute of Cytology, RAS, Saint-Petersburg, Russia \\ Correspondence to: Nickolai A. Barlev, email: nick.a.barlev@gmail.com \\ Salvador Macip, email: sm460@leicester.ac.uk
}

Keywords: BTK; p53; MDM2; phosphorylation; ubiquitination

Received: August 25, $2017 \quad$ Accepted: October 30, $2017 \quad$ Published: November 20, 2017

Copyright: Rada et al. This is an open-access article distributed under the terms of the Creative Commons Attribution License 3.0 (CC BY 3.0), which permits unrestricted use, distribution, and reproduction in any medium, provided the original author and source are credited.

\section{ABSTRACT}

p53 is a tumour suppressor that is activated in response to various types of stress. It is regulated by a complex pattern of over 50 different post-translational modifications, including ubiquitination by the E3 ligase MDM2, which leads to its proteasomal degradation. We have previously reported that expression of Bruton's Tyrosine Kinase (BTK) induces phosphorylation of p53 at the $\mathrm{N}$-terminus, including Serine 15, and increases its protein levels and activity. The mechanisms involved in this process are not completely understood. Here, we show that BTK also increases MDM2 and is necessary for MDM2 upregulation after DNA damage, consistent with what we have shown for other p53 target genes. Moreover, we found that BTK binds to MDM2 on its PH domain and induces its phosphorylation. This suggested a negative regulation of MDM2 functions by BTK, supported by the fact BTK expression rescued the inhibitory effects of MDM2 on p53 transcriptional activity. Indeed, we observed that BTK mediated the loss of the ubiquitination activity of MDM2, a process that was dependent on the phosphorylation functions of BTK. Our data together shows that the kinase activity of BTK plays an important role in disrupting the MDM2-p53 negative feedback loop by acting at different levels, including binding to and inactivation of MDM2. This study provides a potential mechanism to explain how BTK modulates p53 functions.

\section{INTRODUCTION}

p53 is a tetrameric transcription factor that plays a critical role in tumour suppression [1] and prevents the emergence of transformed cells [2]. In response to different stress signals, p53 mainly acts as a transcription factor to induce the expression of genes involved in apoptosis, cell cycle arrest or senescence, among other responses. Notably, p53 regulates the expression of both coding and non-coding genes [3]. p53 functions depend on many factors, including stability, intracellular distribution [4-6], interaction with other proteins [7-11] and post-translational modifications (PTMs) [7, 12-14].
Known p53 PTMs include phosphorylation, acetylation, methylation, ubiquitination, SUMOylation, neddylation, $\mathrm{N}$-acetylglucosamine (O-GlcNAcylation) and poly ADPribosylation [5, 11, 12, 14-17]. Cell fate decisions after p53 induction can be further modulated by other factors, such as intracellular ROS levels $[18,19]$.

It is well accepted that ubiquitination is fundamental regulatory mechanism of many proteins, including p53. The underlying mechanism is the nuclear export and proteasome-mediated degradation of the polyubiquitinated protein $[16,20]$. The most extensively studied E3 ligase for $\mathrm{p} 53$ is MDM2, a p53 target gene that blocks its activity, thus establishing a negative feedback loop $[10,21]$. In 
response to DNA damage, ATM phosphorylates p53 at serine 15 (S15) and induces S20 phosphorylation by Chk2 [22]. Simultaneously, MDM2 is phosphorylated by ATM (on serine 395) [23]), ATR (on serine 407) [24] and c-Abl (near the C-terminus) [25]. The goal of this series of events is to disrupt the ubiquitination of $\mathrm{p} 53$ by MDM2, thus preventing protein degradation in proteasomes and allowing stabilization of the p53 protein [26, 27]. In addition, other studies have shown protein kinase B-mediated MDM2 phosphorylation at S166 and S188, which inhibits MDM2 self-ubiquitination and results in MDM2 stabilization [28-30].

Previous studies have reported phosphorylation of many residues of $\mathrm{p} 53$, including S15, S20, S46, S315, S373, S376, and S392 [31]. Many of these modifications mediate the induction of p53 activity or increase p53 stability through the uncoupling of p53-MDM2 [32]. Phosphorylation of p53 is exerted by a broad range of different kinases, including ATM, ATR, DNA-PK, Chk1 and Chk2 [33]. In response to stress signals, both S15 and S20 are phosphorylated, and this results in an interruption of the p53-MDM2 binding [9, 32]. Furthermore, we have shown that methyltransferase Set7/9 that methylates p53 on K372 also interacts with $\mathrm{Mdm} 2$ thereby sequestering it away into a non-functional complex thereby increasing acetylation and stabilization of the former [34,35].

We previously found that Bruton's Tyrosine Kinase (BTK) induces the phosphorylation of p53 at the $\mathrm{N}$-terminus (mainly at serine 15) and that this has an important effect in its protein levels and activity [36]. BTK is a dual-specificity protein kinase able to phosphorylate both serines and tyrosines [37] that belongs to the Tec family of kinases [38]. It is an essential regulator of $\mathrm{B}$ cell proliferation and survival by being involved in pathways that signal for B cell development and maturation [38]. Although it has been mainly associated with B-cell malignancies [39], some studies have also suggested a pro-apoptotic and tumour suppressor role for BTK [40-44]. We showed that inhibition of BTK interfered with the induction of p53 target genes, which lead to a severe impairment in the induction of p53-mediated apoptosis and senescence [36]. This proves that BTK has an important regulatory role as an upstream component of the p53 pathway and suggests that there could be more unknown targets for its phosphorylation activity implicated in tumour suppression.

Here, we further explore the impact of BTK in the p53 pathway by investigating its effects on MDM2. We found that BTK reinforces its upregulation of $\mathrm{p} 53$ activity by phosphorylating and inhibiting MDM2. Our results confirm the relevance of BTK as a novel modulator of p53 activity and provide a mechanistic explanation for its regulatory role in the p53 pathway.

\section{RESULTS}

\section{BTK induces the expression of MDM2}

We have shown that BTK increases p53 protein levels and activity [36], which can happen in the presence or absence of DNA damage in cells with wild type p53 (Figure 1A). We observed that the expression of BTK also induced the upregulation of MDM2 protein levels in normal and cancer cells with wild type p53, even in the absence of damage (Figure 1B and Supplementary Figure 1A), consistent with the critical role of BTK in the activation of p53 target genes [36]. Indeed, we found that lack of BTK expression decreased the localization of p53 to the MDM2 promoter, as well as that of other target genes, and we also confirmed that BTK overexpression had the opposite effect, as we previously showed [36] (Supplementary Figure 1B). As expected, inhibition of BTK expression suppressed the induction of MDM2 mRNA by DNA damage (Figure 1C).

\section{BTK binds to and phosphorylates MDM2 to increase its levels}

The fact that BTK disrupts the MDM2-p53 regulatory loop raised the possibility that BTK may also have a direct effect on MDM2. To test this, we first explored whether BTK could bind to MDM2. An immunoprecipitation assay indicated that this was indeed the case (Figure 2A). Using different BTK deletion constructs [45] (Figure 2B), we determined that this binding likely takes place at the $\mathrm{PH}$ domain (Figure 2C). Moreover, in vitro kinase assay showed that BTK phosphorylated MDM2 (Figure 2D). Of note, when a kinase dead BTK that could not phosphorylate MDM2 (Figure 2E) was used instead, the induction of MDM2 by BTK was lost (Figure 2F and Supplementary Figure 1C). These data together suggest that BTK binds to MDM2 and phosphorylates it, which induces an increase in MDM2 protein levels.

\section{BTK phosphorylation blocks the negative effects of MDM2 on p53}

Phosphorylation of MDM2 is known to affect its E3 ubiquitin ligase activity [29]. Thus, we hypothesized that although the BTK-dependent phosphorylation of MDM2 increases its protein levels, it could also block its functions. Blunting Mdm2 activity would alleviate the inhibition of $\mathrm{p} 53$ functions by preventing its ubiquitination, which would be consistent with the effects of BTK on p53 levels and activity [36]. Indeed, the simultaneous expression of MDM2 and BTK rescued the negative effects of MDM2 on the induction of bona fide p53 target genes, p21 and PUMA, after DNA damage (Figure 3A and 3B). When 
the kinase dead BTK was used instead, this effect was not observed (Figure 3C), indicating that it depends on the ability of BTK to phosphorylate MDM2. These results prove that although BTK increases MDM2 expression, it also prevents its inhibition of p53 transactivation functions, thus resulting in upregulation of the p53 target genes.

\section{Phosphorylation of MDM2 by BTK suppresses its ubiquitination activity}

To better understand the mechanism involved in this phenomenon, we determined the effects of BTK on the ubiquitination activity of MDM2. As shown in Figure 4A, prior phosphorylation of MDM2 by BTK reduced the MDM2-mediated ubiquitination of p53 and MDM2 itself in vitro. Of note, presence of active BTK also suppressed auto-ubiquitination of MDM2 in vivo (Figure 4B), but not when a dead kinase BTK was used (Figure 4C). An affinity pulldown assay using $\mathrm{Ni}^{2+}$ beads confirmed that p53 was not ubiquitinated in the presence of BTK and that this was reverted when BTK activity was blocked with ibrutinib, a specific inhibitor $[46,47]$ (Figure 4D). Taken together, these results indicate that BTK phosphorylates MDM2 and inhibits its functions, specifically the ubiquitination of p53, which provides a mechanism to explain the increased p53 protein stability induced by BTK [36].

\section{DISCUSSION}

Numerous regulatory mechanisms that affect p53 activity have been extensively studied for decades. Yet, novel additional modulators of p53 are still being discovered and the complexity of its network keeps increasing, which signifies the importance of $\mathrm{p} 53$ functions to the cell. Here, we provide a mechanistic explanation for the modulation of p53 activity by BTK, a newly described component of the p53 regulatory network. We had previously observed that BTK expression increased the stability of p53 and its transactivation abilities [36]. Conversely, blocking BTK reduced the induction of p53 after DNA damage. Consequently, cellular responses to p53 up-regulation, such as apoptosis and senescence, were greatly influenced by the expression of BTK.

We hypothesized that the role of BTK in the response of p53 to stress was determined by the ability of BTK to induce the phosphorylation of p53 at the $N$ terminus and, specifically, at serine 15 . It has been previously shown that the N-terminus phosphorylation serves as the initial response to damaging signals, triggering a cascade of post-transcriptional modifications necessary for p53 stabilization and activation [48]. Thus, the fact that BTK has an impact on these phosphorylation events suggests that it is a key upstream regulator of the p53 pathway.
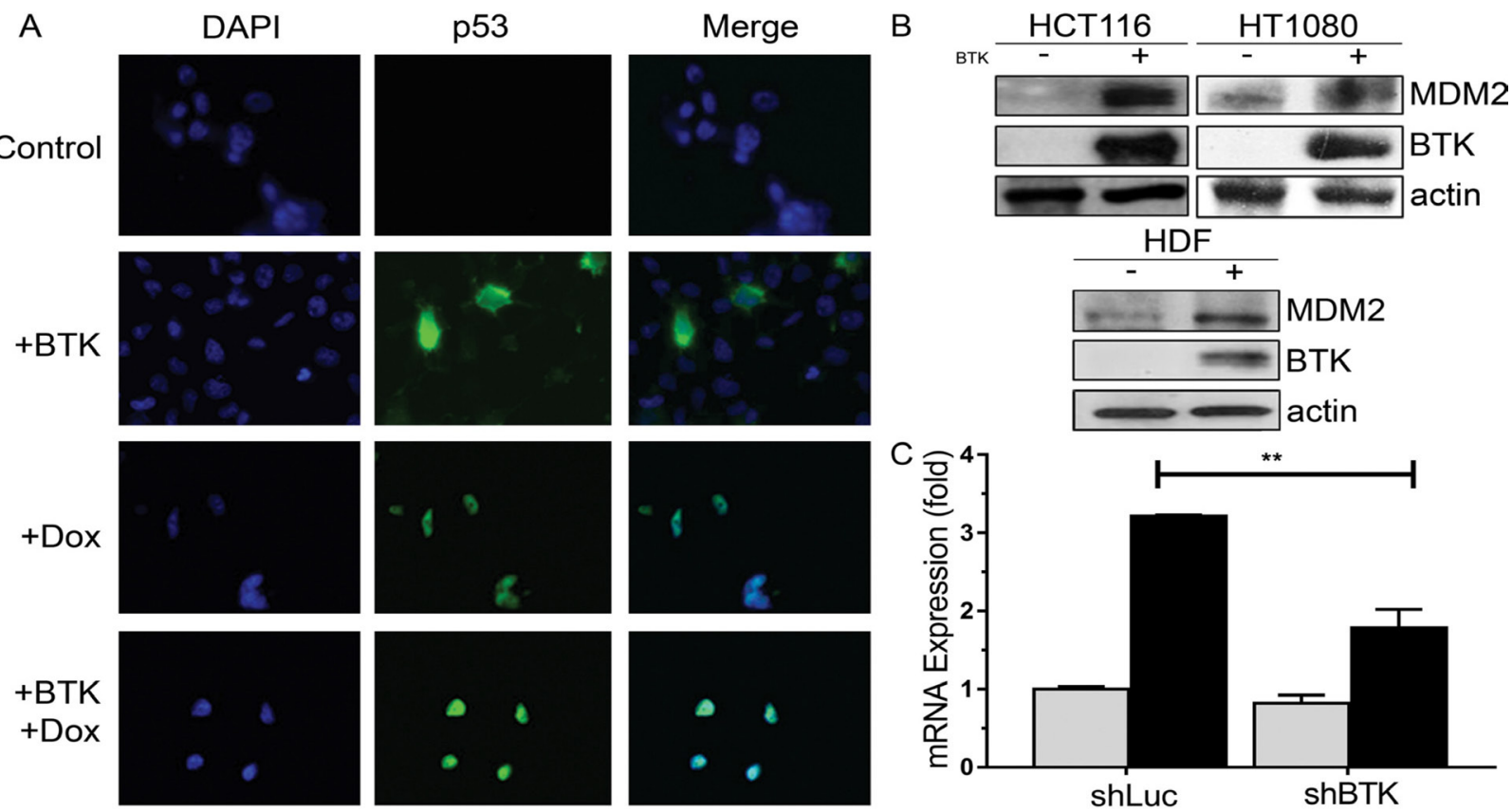

Figure 1: Effects of BTK on MDM2 expression. (A) Representative immunofluorescence images of HCT116 cells transfected with an empty vector (Control) or BTK and treated with $1.5 \mu \mathrm{M}$ doxorubicin for $20 \mathrm{~h}$, showing expression of p53. DAPI is used to stain the DNA (B) Representative Western Blots showing MDM2 and BTK protein levels in lysates of HCT116, HT1080 and HDF transfected with BTK or an empty vector (Control) and all treated with $1.0 \mu \mathrm{M}$ doxorubicin for 24 hours. $\beta$-actin levels are provided as loading controls, as in all other blots. (C) Real time PCR data showing relative expression of MDM mRNA in HCT116 stably transfected with a shRNA against luciferase (shLuc, as a control) or BTK, and treated with $1.5 \mu \mathrm{M}$ doxorubicin for $24 \mathrm{~h}$. Bars represent mean values of three experiments and error bars show standard deviation. ${ }^{* *} p<0.01$. 
In this study, we further elucidated the mechanisms involved in these processes. Loss of MDM2-mediated ubiquitination of p53 is widely associated with p53 phosphorylation at the $N$-terminus [5]. The interplay between phosphorylation and ubiquitination is regulated by two mechanisms: MDM2-p53 uncoupling [49] and inhibition of MDM2 E3 ubiquitin ligase activity [23]. We reasoned that BTK could have an impact on the MDM2-p53 relationship by acting on MDM2 as well. In this report, we show that this is indeed the case.

Our results prove that BTK expression increases the protein levels of MDM2 by binding to it and phosphorylating it. Although it may seem counterintuitive, this is consistent with the fact that MDM2 is a p53 target gene. Therefore, like other p53 targets, it is likely to be upregulated by the BTK-dependent activation of p53, as previously reported [36]. However, we found that this increase in MDM2 levels does not correlate with an increase in its activity. On the contrary, the ability of MDM2 to ubiquitinate p53 or itself was diminished in the presence of BTK. Our data suggest that this inhibition of the ubiquitination functions could be the result of BTK phosphorylating MDM2, although a BTK-mediated phosphorylation of p53 could have an indirect effect as well. Further experiments are needed to determine whether BTK can phosphorylate MDM2 directly, as our binding and in vitro phosphorylation assays would suggest, or there is an indirect mechanism involved. Also, it would be interesting to determine whether BTK may be acting in other ways to reinforce its positive effect on p53 activity.

Our results indicate BTK affects p53 activity at several levels, some of which are yet to be fully characterized. On one hand, phosphorylation of p53 at serine 15 disrupts the MDM2-p53 interaction. At the same time, phosphorylation of MDM2 by the same kinases, including BTK, should reduce its ubiquitination activity. This model underscores the important role of BTK in the facilitation of the p53 pathway and highlights how this goal can be achieved by simultaneous induction of more than one response with a similar outcomes. Moreover, the present report also stresses that the tumour suppressor functions of BTK are important and can be physiologically relevant in the context of preventing the growth of solid tumours. Since BTK inhibitors are already being used clinically to treat different leukaemias, it is urgent to better characterize the mechanisms by which BTK affects the oncogenic and tumour suppressor pathways, in order to avoid unexpected long-term side effects.
A

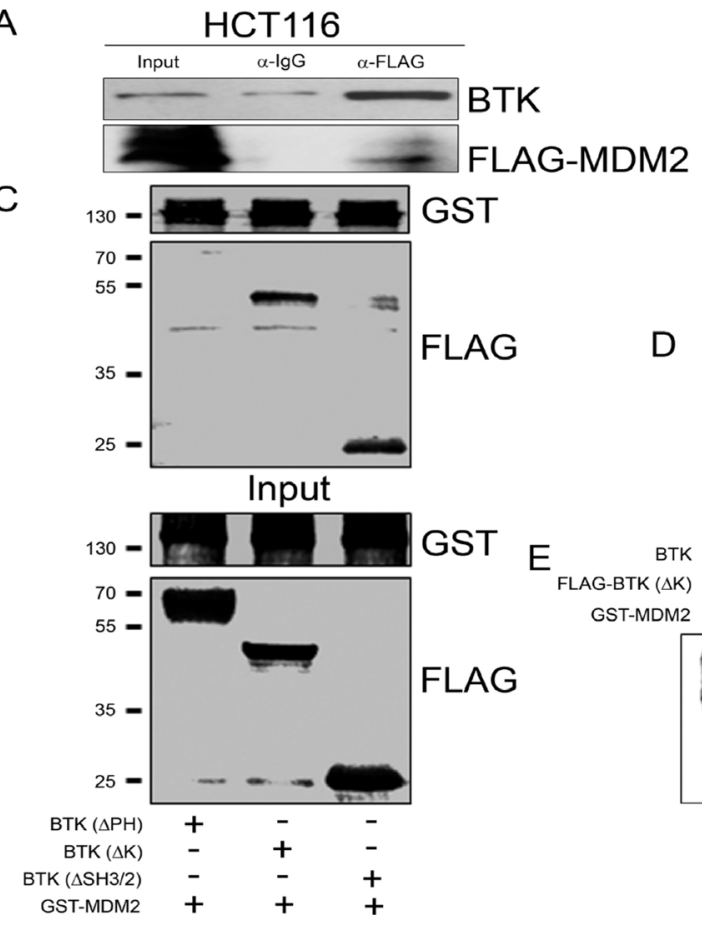

B

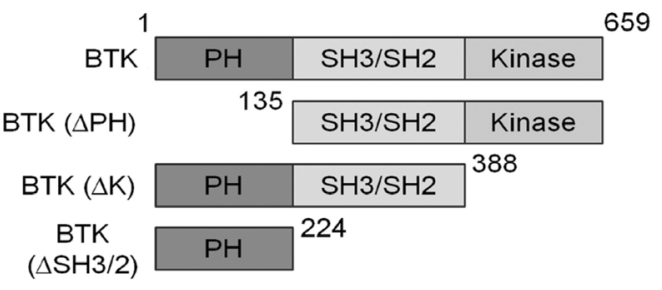

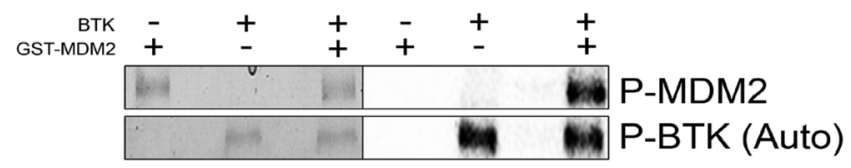

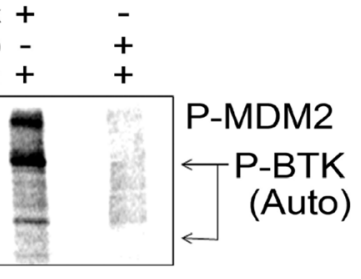

F Control BTK $B T K(\Delta K)$

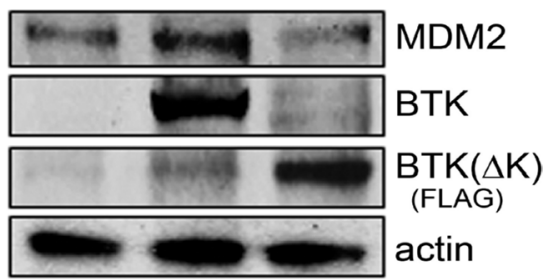

Figure 2: BTK binds to and phosphorylates MDM2. (A) Immunoprecipitation (IP) with lysates of HCT116 transfected with BTK and FLAG-tagged MDM2. IP was performed with a FLAG or IgG antibody and the Western blots used BTK and FLAG antibodies. (B) Schematic representation of the BTK constructs used in C. (C) Binding assay in HCT116 cells transfected with different BTK constructs and GST-tagged MDM2. The top blot shows binding to glutathione beads; the bottom blot shows input levels. Numbers on the left indicate approximate protein weight $(\mathrm{kDa})$. (D) In vitro phosphorylation assay showing phosphorylation of MDM2 by BTK as well as BTK autophosphorylation. (E) Same as (D) using a wild type BTK construct or a FLAG-tagged BTK lacking the kinase domain (BTK( $\triangle K)$ ). (F) Western blots showing MDM2 and BTK protein levels in lysates of HT1080 transfected with an empty vector (Control), BTK or FLAG-BTK $(\Delta \mathrm{K})$, with all samples treated with $1.5 \mu \mathrm{M}$ doxorubicin for $24 \mathrm{~h}$. 


\section{MATERIALS AND METHODS}

\section{Plasmid constructs}

The plasmids generated and used were pGL3-p21, pCDNA3-p53, pSV- $\beta$-Gal, CMV6-, pGEX-6HisUbiquitin, pGEX-MDM2 and pCDNA3-FLAG-MDM2, as well as BTK (OriGene RG211582). pCDNA3 was used as empty vector for controls.

\section{Cell culture and transient transfections.}

HCT116 colon cancer cell line (with wt p53), HT1080 osteosarcoma cell line (with wt p53) and human diploid fibroblasts (HDF) were cultured in DMEM and incubated at $37^{\circ} \mathrm{C}$ with $5 \% \mathrm{CO}_{2}$. After $24-48$ hours, media was changed. Cells were cultured and grown until $70-80 \%$ was reached, and transfections were carried with Turbofect (Thermo Scientific, \# R0531), following manufacturer's instructions. Dilution of plasmids was performed in serum-free medium (Opti-MEM, GIBCO, Life Technologies). Cells were incubated with the plasmid/ Turbofect mix for 24-48 hours and then collected. $1.5 \mu \mathrm{M}$ doxorubicin (Sigma-Aldrich) was added to induce DNA damage. $0.5 \mu \mathrm{M}$ Ibrutinib (Sellechem, PCI-32765) was used to inhibit BTK. $2 \mu \mathrm{M}$ MG-132 was used to inhibit the proteasome.

\section{Immunoblot analysis}

For lysate extraction, the medium was removed and plates were washed once with 1x PBS, trypsinized, collected and kept on ice. Cells were ruptured by passing through a syringe 5 times or with sonication, and centrifuged for 15 minutes. The supernatant was transferred into Eppendorf tubes, and protein concentrations were determined using the Bradford protein assay (Fermentas). 10-20 $\mu \mathrm{g}$ of total protein per sample
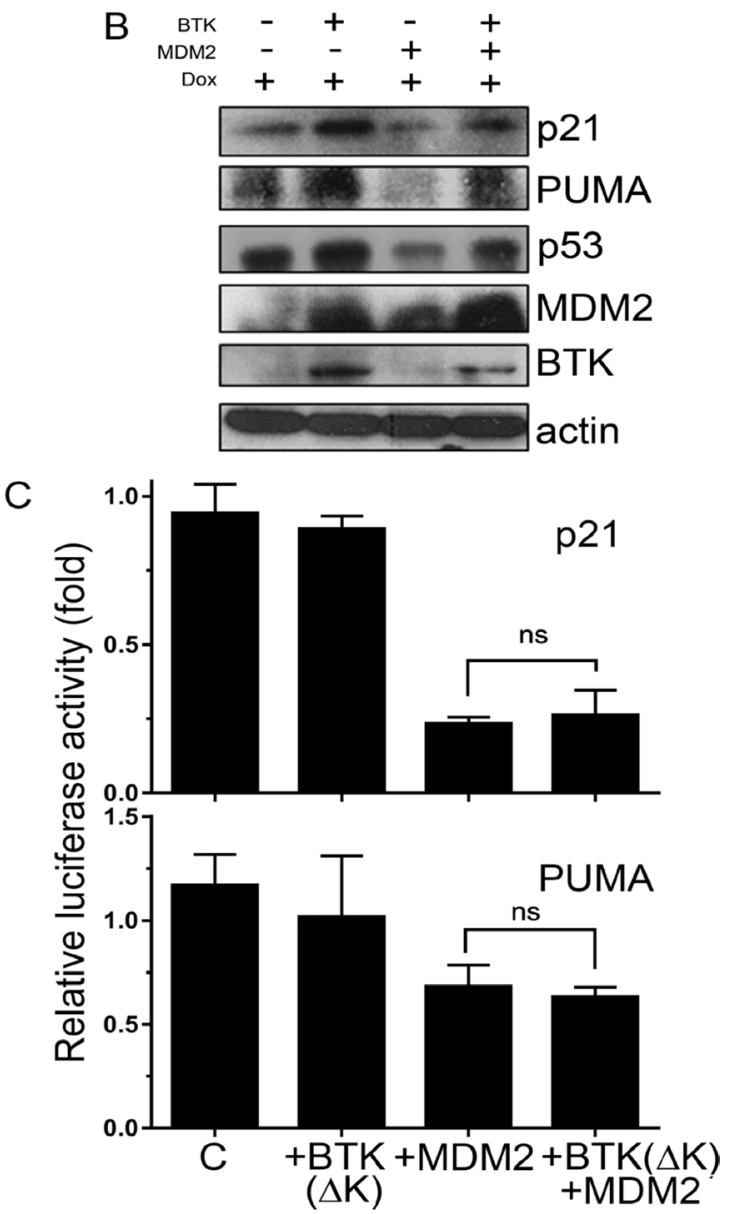

Figure 3: BTK prevents MDM2 inhibition of p53 transactivation functions. (A) Relative luciferase activity of p21 and PUMA reporters in HCT116 cells in which BTK and/or MDM2 has been transfected $24 \mathrm{~h}$ before, in the absence or presence of $1.5 \mu \mathrm{M}$ doxorubicin for $24 \mathrm{~h}$. Control cells (C) were transfected with an empty vector. Graphs represent mean of a triplicate experiment, error bars represent standard deviation. ns: non significant; ${ }^{*} P \leq 0.05 ;{ }^{* *} P \leq 0.01$. (B) Western blot showing protein levels of p21, PUMA, p53, MDM2 and BTK in the same cells. (C) Relative luciferase activity of p21 and PUMA reporters in HCT116 cells in which BTK( $\triangle \mathrm{K})$ and/or MDM2 have been transfected $24 \mathrm{~h}$ before, all in the presence of $1.5 \mu \mathrm{M}$ doxorubicin for $24 \mathrm{~h}$. Control cells (C) were transfected with an empty vector. 
were subjected to $10 \%$ or $6 \%$ SDS-PAGE and transferred to Immobilon-P membranes (Millipore). Primary antibodies used were: $\beta$-actin (Abcam, \#ab8227), p53 (Calbiochem, \#Op43), p21 (Santa Cruz Biotechnology, \#sc-53870), PUMA (Cell Signalling, \#4976), BTK (Cell Signalling, \#8547S), MDM2 (Abcam, \#ab137413) and Streptavidin-Biotinylated HRP Complex (GE Healthcare, \# RPN1051).

\section{ChIP assays}

ChIP assays were performed as previously described [36]. $3 \times 10^{6}$ cells per sample were used. PCR was performed with $1 \mu \mathrm{l}$ of DNA. The p53 (Ab-6, Galbichem\#OP43) antibody was used. Primers used: 5'mdm2 (GGTTGACTCAGCTTTTCCTCTTG), 3'-mdm2 (GGAAAATGCATGGTTTAAATAGCC), 5-Puma: (GCG AGACTGTGGCCTTGTGT), 3'-Puma (CGTTCCAGG GTCCACAAAGT)， 5'-p21 (GTGGCTCTGATTGGC TTTCTG), 3'-p21 (CTGAAAACAGGCAGCCCAAG).

\section{Protein-protein interactions}

For in vivo protein-protein binding assays, cells were transfected with FLAG-MDM2 and BTK, and lysed in lysis buffer (PBS, $50 \mathrm{mM} \mathrm{NaCl}, 1 \% \mathrm{NP}-40$, $1 \mathrm{mM}$ PMSF) at $4^{\circ} \mathrm{C}$. Proteins were immunoprecipitated with anti-IgG (Santa Cruz Biotechnology, \# sc-2025), or anti-FLAG antibodies overnight at $4^{\circ} \mathrm{C}$, and then protein $\mathrm{A} / \mathrm{G}$ agarose beads (Millipore, \#16-157) were added for $4 \mathrm{~h}$ with rotation at $4^{\circ} \mathrm{C}$. Bound proteins were analysed by Western blotting. For in vitro protein-protein binding assays, cells were transfected with FLAG tagged BTK plasmid (BTK $(\Delta \mathrm{PH}), \mathrm{BTK}(\Delta \mathrm{K})$, or BTK $(\Delta \mathrm{SH} 3 / 2))$. The cells were lysed and BTK proteins were prepared by immunoprecipitation using anti-FLAG antibody. The purified BTK proteins were mixed with GST-MDM2 individually and incubated for 4 hours with rotation at $4^{\circ} \mathrm{C}$. The mixtures were added to glutathione HiCap matrix beads (Qiagen \#30900) and incubated for 4 hours at $4^{\circ} \mathrm{C}$ with rotation. The beads were washed with PBS and eluted, followed by Western blotting using anti-GST and anti-FLAG antibodies.

\section{$\mathrm{Ni}^{2+-}$ TTA beads pulldown}

Cells were transfected with BTK and 6HisUbiquitin vectors, and after 24 hours treated with MG132 (Sigma-Aldrich, \#M7449), for 12 hours. Cells were then lysed with 6M Guanidine hydrochloride (Sigma-Aldrich, \#G3272), and 6His-ubiquitinated proteins were purified on Ni-NTA beads (Qiagen, \#30210). The bound proteins were eluted and analysed by immunoblotting with p53-specific antibody (Calbiochem, \#Op43).

\section{Luciferase reporter assay}

100,000 cells per well were seeded in $0.5 \mathrm{ml}$ growth media in 24-well plates. The following day, transfection was performed following the protocol described above. $1.0 \mu \mathrm{g}$ total plasmid DNA $(0.3 \mu \mathrm{g}$ luciferase construct, $0.2 \mu \mathrm{g} \beta$-galactosidase construct, and $0.5 \mu \mathrm{g}$ empty
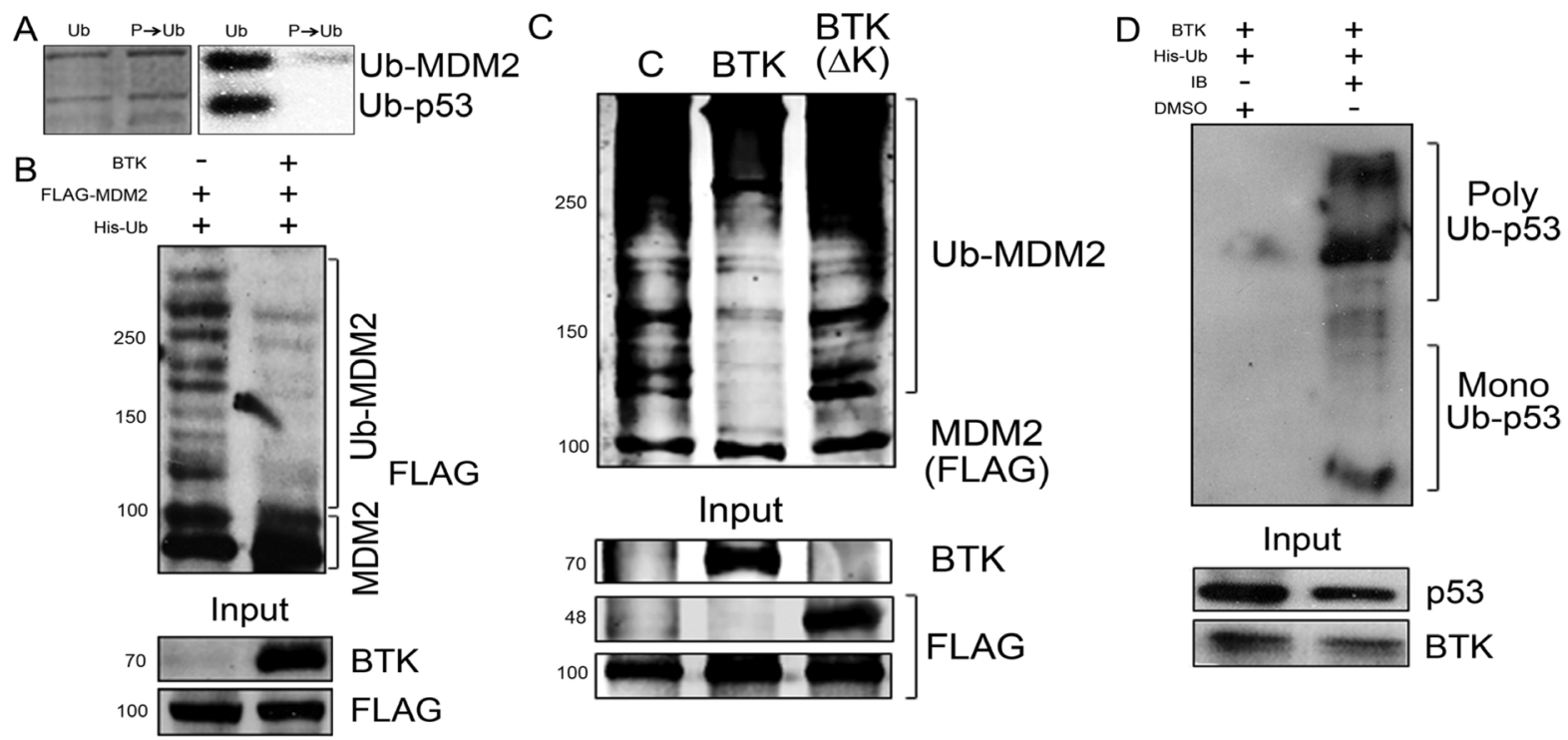

Figure 4: BTK inhibits MDM2 ubiquitination activity. (A) In vitro ubiquitination assay of p53 and GST-tagged MDM2, before or after using BTK to phosphorylate MDM2. Left panel shows total amounts of protein loaded in the gel and right panel shows a Western blot of ubiquitinated proteins. (B) In vivo ubiquitination assay using HT1080 cells transfected with BTK and FLAG-tagged MDM2. (C) In vivo ubiquitination assay using HT1080 cells transfected with an empty vector (C), BTK or FLAG-BTK $(\Delta K)$. All samples were also transfected with FLAG-MDM2 and His-Ubiquitin. Numbers on the left indicate approximate protein weight (kDa). (D) Same as B, in HCT116 cells treated or not with $0.5 \mu \mathrm{M}$ ibrutininb (IB) for $24 \mathrm{~h}$, showing poly- and mono-ubiquitinated $\mathrm{p} 53$. 
control vector or BTK construct) was used. 24 hours after transfection, media was replaced and part cells treated with $1.0 \mu \mathrm{M}$ Doxorubicin. 24 hours later, lysates were collected in lysis buffer and stored at $-80^{\circ} \mathrm{C}$ overnight. Prior evaluation, $\beta$-galactosidase substrate $(10 \mathrm{ml}$ of $\beta$-galactosidase stock solution, $20 \mathrm{mg}$ o-nitrophenyl- $\beta$-dgalactopyranoside (ONPG) and $35 \mu \mathrm{l} \beta$-mercaptoethanol) was prepared and $100 \mu \mathrm{l}$ was added to $80 \mu \mathrm{l}$ cell lysate (per well) in a 96-well transparent plate. This was incubated at $37^{\circ} \mathrm{C}$ for 15 minutes. $20 \mu$ of the cell lysate were transferred to a 96-well opaque white plate and read in a luminometer, using a luciferase kit (BioVision\#K801-200), as previously described [50].

\section{Quantitative real-time PCR}

RNA purification, cDNA preparation, and qRT-PCR were performed as previously described [51]. Primers used: GAPDH: GGGAAGGTGAAGGTCGGAGT (FWD), TTGAGGTCAATGAAGGGGTCA (REV). MDM2: TGGCGTGCCAAGCTTCTCTGT (FWD), ACCTGAGTCCGATGATTCCTGCT (REV).

\section{In vitro kinase assay}

Full length Recombinant BTK (Invitrogen, PV3363), p53, and MDM2 were used in this study, the GSTtagged p53 and MDM2 were obtained by transfecting the appropriate pGEX vectors into BL21 competent and purifying the proteins produced with glutathione HiCap matrix beads (Qiagen \#30900), as previously described [52]. $0.5 \mu \mathrm{g}$ BTK and $0.5 \mu \mathrm{g}$ p53 or MDM2 were added in a tube containing $25 \mu$ of kinase buffer (12.5 mM Tris- $\mathrm{HCl}$ (pH7.5), $10 \mathrm{mM} \mathrm{MgCl2,} 1$ mM EGTA, $0.5 \mathrm{mM}$ Na3 VO4, $5 \mathrm{mM} \beta$-Glycerophosphate, $0.01 \%$ Triton $\mathrm{X}-100,2$ mM DTT, $200 \mu \mathrm{M}$ ATP). Approximately $0.37 \mathrm{MBq}$ of $[32 \mathrm{P}] \gamma$-ATP was added to each tube for $30 \mathrm{~min}$ at $30^{\circ} \mathrm{C}$. Loading buffer was then added to each sample, and samples were boiled for $5 \mathrm{~min}$ and loaded into a $10 \%$ polyacrylamide gel. The gel was then dried using a Model v583 Gel drier (Biorad) for 1 hour and exposed to film in a Phosphor screen (GH Healthcare) overnight at room temperature. Phosphoimage of dried gel was then developed using a Typhoon TRIO+ Variable mode manger scanner (GE Healthcare).

\section{In vitro ubiquitination assay}

An in vitro ubiquitination assay was performed using an ubiquitination kit (Enzo Life Science, \#BMLUW9920-0001). The GST-tagged p53 and MDM2 were obtained by transfecting the appropriate pGEX vectors into BL21 competent and purifying the proteins produced with glutathione HiCap matrix beads (Qiagen \#30900), as previously described [52] and the reaction was prepared as follows: 10x ubiquitination buffer, $50 \mathrm{mM}$ DTT, 0.1 M Mg-ATP, 20x E1 (His6-tagged recombinant human ubiquitin-activating enzyme), 10x E2 (His6- tagged recombinant human ubiquitin-conjugating enzyme UbcH7), 20x or $0.5 \mu \mathrm{g}$ of E3 (GST-MDM2), 20x biotinylated ubiquitin, and $20 \mathrm{x}$ or $0.5 \mu \mathrm{g}$ of target protein (GST-tagged full-length p53). This was incubated for 60 minutes at $37^{\circ} \mathrm{C}$. The reaction was stopped by adding $10 \mu \mathrm{l} 4 \mathrm{x}$ SDS-PAGE loading buffer and boiled for 5 minutes. $20 \mu \mathrm{l}$ of the samples were run on SDS-PAGE gels and transferred to membranes. The amount and size of loaded protein was verified in one of the membranes using Instant Blue stain for 15 minutes at room temperature while rocking. The efficiency of ubiquitination was confirmed performing Western blotting on the second membrane.

\section{Immunofluorescence}

Cells were processed and transfected following previously described protocols [53]. Cells were fixed using $4 \%$ paraformaldehyde, washed with PBS and permeabilised with $0.1 \%$ Triton X-100. Cells were then washed with PBS and blocked with 1\% BSA. Coverslips were incubated overnight at $4^{\circ} \mathrm{C}$ with 1:100 anti-MDM2 (Abcam, \#ab137413) or. The following day, coverslips were washed with PBS and incubated with $100 \mu$ of 1:500 secondary anti-rabbit (Thermo Scientific, \#84540) or anti-mouse antibody (Thermo Scientific, \#35552) for 45 minutes in the dark. After incubation, coverslips were washed three times with PBS and stained with 4',6-Diamidino-2-Phenylindole, Dihydrochloride (DAPI, Invitrogen) for 10 minutes. Slides were analysed using a Nokia TE300 semi-automatic microscope. The fluorescence intensity was measured using ImageJ analysis software (NIH, Bethesda, MD).

\section{Statistical analysis}

All error bars represent the SD. Statistical significance (not significant, ns, $P>0.05$; ${ }^{*} P \leq 0.05$; $\left.{ }^{* *} P \leq 0.01 ;{ }^{* * *} P \leq 0.001 ;{ }^{* * * *} P \leq 0.0001\right)$ was calculated using two-tailed unpaired $t$ tests with Prism 6 (GraphPad) software.

\section{Author contributions}

MR and SM designed the experiments, analysed the data and prepared the manuscript, with help from NB. KPL also contributed. MR performed the experiments, with help from MA, AEE and KGL. All authors reviewed the manuscript.

\section{ACKNOWLEDGMENTS}

NB and OF acknowledges funding from RSCF (grant 14-15-00816) and MCB Program at RAS.

\section{CONFLICTS OF INTEREST}

The authors declare no conflicts of interest. 


\section{FUNDING}

Work in SM's lab was supported by an MRC New Blood Fellowship and an Innovation Fellowship from the University of Leicester and the M.C. Andreu Memorial Fund. MR was supported by a Doctoral Studentship from the Kurdistan Regional Government (Iraq). MA was supported by a Saudi Government Doctoral Scholarship. NB and OF acknowledges funding from RSCF (grant 14-15-00816).

\section{REFERENCES}

1. Weinberg RL, Veprintsev DB, Fersht AR. Cooperative binding of tetrameric p53 to DNA. J Mol Biol. 2004; 341:1145-1159.

2. Stiewe T. The p53 family in differentiation and tumorigenesis. Nat Rev Cancer. 2007; 7:165-168.

3. Barlev NA, Sayan BS, Candi E, Okorokov AL. The microRNA and p53 families join forces against cancer. Cell Death Differ. 2010; 17:373-375.

4. Vousden KH, Ryan KM. p53 and metabolism. Nat Rev Cancer. 2009; 9:691-700.

5. Olsson A, Manzl C, Strasser A, Villunger A. How important are post-translational modifications in p53 for selectivity in target-gene transcription and tumour suppression? Cell Death Differ. 2007; 14:1561-1575.

6. Sionov RV, Hayon IL, Haupt Y. The Regulation of p53 Growth Suppression. Madame Curie Bioscience Database. Austin (TX): Landes Bioscience. 2000-2013.

7. Fernandez-Fernandez MR, Sot B. The relevance of proteinprotein interactions for $\mathrm{p} 53$ function: the CPE contribution. Protein Eng Des Sel. 2011; 24:41-51.

8. Bai L, Zhu WG. p53: Structure, Function and Therapeutic Applications. J Cancer Mol. 2006; 2:141-153.

9. Kruse JP, Gu W. Modes of p53 regulation. Cell. 2009; 137:609-622.

10. Laine A, Ronai Z. Regulation of p53 localization and transcription by the HECT domain E3 ligase WWP1. Oncogene. 2007; 26:1477-1483.

11. Muller PA, Vousden KH. p53 mutations in cancer. Nat Cell Biol. 2013; 15:2-8.

12. Dai $\mathrm{C}, \mathrm{Gu}$ W. p53 post-translational modification: deregulated in tumorigenesis. Trends Mol Med. 2010; 16:528-36.

13. Scoumanne A, Chen X. Protein methylation: a new mechanism of p53 tumor suppressor regulation. Histol Histopathol. 2008; 23:1143-1149.

14. Smeenk L, van Heeringen SJ, Koeppel M, Gilbert B, Janssen-Megens E, Stunnenberg HG, Lohrum M. Role of p53 serine 46 in p53 target gene regulation. PLoS One. 2011; 6:e17574.
15. Jenkins LM, Durell SR, Mazur SJ, Appella E. p53 N-terminal phosphorylation: a defining layer of complex regulation. Carcinogenesis. 2012; 33:1441-1449.

16. Li M, Brooks CL, Wu-Baer F, Chen D, Baer R, Gu W. Mono- versus polyubiquitination: differential control of p53 fate by Mdm2. Science. 2003; 302:1972-1975.

17. Marouco D, Garabadgiu AV, Melino G, Barlev NA. Lysinespecific modifications of p53: a matter of life and death? Oncotarget. 2013; 4:1556-71. https://doi.org/10.18632/ oncotarget.1436.

18. Macip S, Igarashi M, Berggren P, Yu J, Lee SW, Aaronson SA. Influence of induced reactive oxygen species in p53mediated cell fate decisions. Mol Cell Biol. 2003; 23:8576-8585.

19. Masgras I, Carrera S, de Verdier PJ, Brennan P, Majid A, Makhtar W, Tulchinsky E, Jones GD, Roninson IB, Macip S. Reactive oxygen species and mitochondrial sensitivity to oxidative stress determine induction of cancer cell death by p21. J Biol Chem. 2012; 287:9845-9854.

20. Lee JT, Gu W. The multiple levels of regulation by $\mathrm{p} 53$ ubiquitination. Cell Death Differ. 2010; 17:86-92.

21. Cheng Q, Chen L, Li Z, Lane WS, Chen J. ATM activates p53 by regulating MDM2 oligomerization and E3 processivity. EMBO J. 2009; 28:3857-3867.

22. Cheng Q, Chen J. Mechanism of p53 stabilization by ATM after DNA damage. Cell Cycle. 2010; 9:472-478.

23. Maya R, Balass M, Kim ST, Shkedy D, Leal JF, Shifman O, Moas M, Buschmann T, Ronai Z, Shiloh Y, Kastan MB, Katzir E, Oren M. ATM-dependent phosphorylation of $\mathrm{Mdm} 2$ on serine 395: role in p53 activation by DNA damage. Genes Dev. 2001; 15:1067-1077.

24. Shinozaki T, Nota A, Taya Y, Okamoto K. Functional role of Mdm2 phosphorylation by ATR in attenuation of p53 nuclear export. Oncogene. 2003; 22:8870-8880.

25. Sionov RV, Coen S, Goldberg Z, Berger M, Bercovich B, Ben-Neriah Y, Ciechanover A, Haupt Y. c-Abl regulates p53 levels under normal and stress conditions by preventing its nuclear export and ubiquitination. Mol Cell Biol. 2001; 21:5869-5878.

26. Xu H, Ye H, Osman NE, Sadler K, Won EY, Chi SW, Yoon HS. The MDM2-binding region in the transactivation domain of p53 also acts as a Bcl-X(L)-binding motif. Biochemistry. 2009; 48:12159-12168.

27. Grigoreva TA, Tribulovich VG, Garabadzhiu AV, Melino G, Barlev NA. The 26S proteasome is a multifaceted target for anti-cancer therapies. Oncotarget. 2015; 6:24733-49. https://doi.org/10.18632/oncotarget.4619.

28. Cheng Q, Cross B, Li B, Chen L, Li Z, Chen J. Regulation of MDM2 E3 Ligase Activity by Phosphorylation after DNA Damage. Mol Cell Biol. 2011; 31:4951-4963.

29. Feng J, Tamaskovic R, Yang Z, Brazil DP, Merlo A, Hess D, Hemmings BA. Stabilization of Mdm2 via 
decreased ubiquitination is mediated by protein kinase B/Akt-dependent phosphorylation. J Biol Chem. 2004; 279:35510-35517.

30. Ranaweera RS, Yang X. Auto-ubiquitination of Mdm2 enhances its substrate ubiquitin ligase activity. J Biol Chem. 2013; 288:18939-18946.

31. Warnock LJ, Adamson R, Lynch CJ, Milner J. Crosstalk between site-specific modifications on p53 and histone H3. Oncogene. 2008; 27:1639-1644.

32. Loughery J, Meek D. Switching on p53: an essential role for protein phosphorylation? BioDiscovery. 2013; 8:1.

33. Durocher D, Jackson SP. DNA-PK, ATM and ATR as sensors of DNA damage: variations on a theme? Curr Opin Cell Biol. 2001; 13:225-231.

34. Lezina L, Aksenova V, Fedorova O, Malikova D, Shuvalov O, Antonov AV, Tentler D, Garabadgiu AV, Melino G, Barlev NA. KMT Set7/9 affects genotoxic stress response via the Mdm2 axis. Oncotarget. 2015; 6:25843-55. https://doi. org/10.18632/oncotarget.4584.

35. Lezina L, Aksenova V, Ivanova T, Purmessur N, Antonov AV, Tentler D, Fedorova O, GarabadgiuAV, Talianidis I, Melino G, Barlev NA. KMTase Set7/9 is a critical regulator of E2F1 activity upon genotoxic stress. Cell Death Differ. 2014; 21:1889-1899.

36. Althubiti M, Rada M, Samuel J, Escorsa JM, Najeeb H, Lee KG, Lam KP, Jones GD, Barlev NA, Macip S. BTK Modulates p53 Activity to Enhance Apoptotic and Senescent Responses. Cancer Res. 2016; 76:5405-5414.

37. Yang EJ, Yoon JH, Chung KC. Bruton's tyrosine kinase phosphorylates cAMP-responsive element-binding protein at serine 133 during neuronal differentiation in immortalized hippocampal progenitor cells. J Biol Chem. 2004; 279:1827-1837.

38. Mohamed AJ, Yu L, Backesjo CM, Vargas L, Faryal R, Aints A, Christensson B, Berglof A, Vihinen M, Nore BF, Smith CI. Bruton's tyrosine kinase (Btk): function, regulation, and transformation with special emphasis on the PH domain. Immunol Rev. 2009; 228:58-73.

39. Hendriks RW, Yuvaraj S, Kil LP. Targeting Bruton's tyrosine kinase in B cell malignancies. Nat Rev Cancer. 2014; 14:219-232.

40. Islam TC, Branden LJ, Kohn DB, Islam KB, Smith CI. BTK mediated apoptosis, a possible mechanism for failure to generate high titer retroviral producer clones. J Gene Med. 2000; 2:204-209.

41. Kawakami Y, Miura T, Bissonnette R, Hata D, Khan WN, Kitamura T, Maeda-Yamamoto M, Hartman SE, Yao L, Alt FW, Kawakami T. Bruton's tyrosine kinase regulates apoptosis and JNK/SAPK kinase activity. Proc Natl Acad Sci U S A. 1997; 94:3938-3942.

42. Kersseboom R, Middendorp S, Dingjan GM, Dahlenborg K, Reth M, Jumaa H, Hendriks RW. Bruton's tyrosine kinase cooperates with the B cell linker protein SLP-65 as a tumor suppressor in Pre-B cells. J Exp Med. 2003; 198:91-98.

43. Middendorp S, Zijlstra AJ, Kersseboom R, Dingjan GM, Jumaa H, Hendriks RW. Tumor suppressor function of Bruton tyrosine kinase is independent of its catalytic activity. Blood. 2005; 105:259-265.

44. Ta VB, de Bruijn MJ, ter Brugge PJ, van Hamburg JP, Diepstraten HJ, van Loo PF, Kersseboom R, Hendriks RW. Malignant transformation of Slp65-deficient pre-B cells involves disruption of the Arf-Mdm2-p53 tumor suppressor pathway. Blood. 2010; 115:1385-1393.

45. Lee KG, Kim SS, Kui L, Voon DC, Mauduit M, Bist P, Bi X, Pereira NA, Liu C, Sukumaran B, Renia L, Ito Y, Lam KP. Bruton's tyrosine kinase phosphorylates DDX41 and activates its binding of dsDNA and STING to initiate type 1 interferon response. Cell Reports. 2015; 10:1055-1065.

46. Brown JR, Barrientos JC, Barr PM, Flinn IW, Burger JA, Tran A, Clow F, James DF, Graef T, Friedberg JW, Rai K, O'Brien S. The Bruton tyrosine kinase inhibitor ibrutinib with chemoimmunotherapy in patients with chronic lymphocytic leukemia. Blood. 2015; 125:2915-22.

47. Pan Z, Scheerens H, Li SJ, Schultz BE, Sprengeler PA, Burrill LC, Mendonca RV, Sweeney MD, Scott KC, Grothaus PG, Jeffery DA, Spoerke JM, Honigberg LA, et al. Discovery of selective irreversible inhibitors for Bruton's tyrosine kinase. ChemMedChem. 2007; 2:58-61.

48. Gu B, Zhu WG. Surf the post-translational modification network of p53 regulation. Int J Biol Sci. 2012; 8:672-684.

49. Sakaguchi K, Saito S, Higashimoto Y, Roy S, Anderson CW, Appella E. Damage-mediated phosphorylation of human p53 threonine 18 through a cascade mediated by a casein 1-like kinase. Effect on Mdm2 binding. J Biol Chem. 2000; 275:9278-9283.

50. Rada M, Vasileva E, Lezina L, Marouco D, Antonov AV, Macip S, Melino G, Barlev NA. Human EHMT2/G9a activates p53 through methylation-independent mechanism. Oncogene. 2017; 36:922-32.

51. Carrera S, Senra J, Acosta MI, Althubiti M, Hammond EM, de Verdier PJ, Macip S. The role of the HIF-1alpha transcription factor in increased cell division at physiological oxygen tensions. PloS one. 2014; 9:e97938.

52. Barlev NA, Liu L, Chehab NH, Mansfield K, Harris KG, Halazonetis TD, Berger SL. Acetylation of p53 activates transcription through recruitment of coactivators/histone acetyltransferases. Mol Cell. 2001; 8:1243-1254.

53. Althubiti M, Lezina L, Carrera S, Jukes-Jones R, Giblett SM, Antonov A, Barlev N, Saldanha GS, Pritchard CA, Cain K, Macip S. Characterization of novel markers of senescence and their prognostic potential in cancer. Cell Death Dis. 2014; 5:e1528. 